\title{
Family Medicine With Refugee Newcomers During the COVID-19 Pandemic
}

\author{
Jackson Andrew Smith, MA, Jean de Dieu Basabose, PhD, \\ Margaret Brockett, BSR (OT), EdD, Dillon Thomas Browne, PhD, C. Psych, \\ Sandy Shamon, MD, CCFP(PC), and Michael Stephenson, MD
}

\begin{abstract}
Certain members of society are disproportionately affected by the COVID-19 crisis and the added strain being placed on already overextended health care systems. In this article, we focus on refugee newcomers. We outline vulnerabilities refugee newcomers face in the context of COVID-19, including barriers to accessing health care services, disproportionate rates of mental health concerns, financial constraints, racism, and higher likelihoods of living in relatively higher density and multigenerational dwellings. In addition, we describe the response to COVID-19 by a community-based refugee primary health center in Ontario, Canada. This includes how the clinic has initially responded to the crisis as well as recommendations for providing services to refugee newcomers as the CoVID-19 crisis evolves. Recommendations include the following actions: (1) consider social determinants of health in the new context of COVID-19; (2) provide services through a trauma-informed lens; (3) increase focus on continuity of health and mental health care; (4) mobilize International Medical Graduates for triaging patients based on COVID-19 symptoms; and (5) diversify communication efforts to educate refugees about CoVID-19. (J Am Board Fam Med 2021;34:S210-S216.)
\end{abstract}

Keywords: Access to Health Care, Community Health Centers, Community Medicine, CoVID-19, Cross-Cultural Comparison, Family Medicine, Mental Health, Minority Health, Ontario, Refugees, Social Determinants of Health

Family Medicine With Refugees During the COVID-19 Crisis

Amid the evolving COVID-19 crisis, health care systems are being pushed beyond their capacities and access to health care is of growing concern across communities and nations. These challenges are significant for all citizens, as the crisis threatens the timely and adequate provision of care to those affected and those who are most vulnerable. In

This article was externally peer reviewed.

Submitted 26 March 2020; revised 22 May 2020; accepted 26 May 2020.

From the Department of Psychology, University of Waterloo, Waterloo, Ontario, Canada (JAS, JDB, DTB); Centre for Mental Health Research and Treatment (CMHRT), University of Waterloo, Waterloo, Ontario, Canada (JAS, DTB); Sanctuary Refugee Health Centre, Kitchener, Ontario, Canada (JDB, MB, MS); Michael G. DeGroote School of Medicine, McMaster University, Hamilton, Ontario, Canada (SS).

Funding: None.

Conflict of interest: We have no conflicting or competing interests to declare.

Corresponding author: Dillon Browne, PhD, C. Psych, Department of Psychology, University of Waterloo, 200 University Ave W, Waterloo, ON, Canada N2L3G1 (E-mail: dillon.browne@uwaterloo.ca). addition, there are many who are disproportionately affected by the profound disruption in accessing services in the context of pre-existing experiences of marginalization and trauma. In this article, we specifically outline some of the vulnerabilities of refugee newcomers (which may also apply to other vulnerable groups), while sharing the initial experiences of a general practice devoted to community-based health care for refugee newcomers in a midsized urban setting in Ontario, Canada. The purpose of this article is to provide an illustrative example for other family health teams and public health organizations who serve refugee newcomers during the ongoing fight against COVID-19.

\section{Challenges for Refugee Newcomers During COVID-19}

Like other vulnerable groups, refugee newcomers are particularly affected during the COVID-19 pandemic due to the exacerbation of factors that already hinder their access to the health care services. Barriers include lack of linguistically and culturally 
appropriate/sensitive care, low socioeconomic status (SES), and fear of accessing care. ${ }^{1-3}$ In addition, refugees experience disproportionately higher rates of mental health concerns due to their exposure to premigration traumas. ${ }^{4-6}$ During the COVID-19 crisis, the capacity of health care systems to address these barriers and provide care sensitive to linguistically and culturally diverse patients is reduced as emergency measures increasingly take priority.

Low SES poses a significant barrier to accessing health care. ${ }^{7-9}$ For people living in countries without universal health care coverage (like the United States), the costs of accessing treatment and health care insurance can be insurmountable. In countries that provide universal health care coverage (like Canada), there are transitional periods during which newcomers are ineligible for health insurance. Beyond the direct costs of health care, individuals and families may also deal with challenges related to transportation to and from health care facilities, especially those who live in rural communities or other areas not serviced by public transit.

In the context of COVID-19, prohibiting the presence of family members or trusted friends during appointments can be an important deterrent due to patients' perceived sense of safety or other cultural factors, such as the importance of receiving same sex care, or other assumptions about the role of medical professionals. ${ }^{10}$ Beyond cultural reasons, fears related to concerns about being denied services or being sent back to one's country of origin if they seek help can also lead refugees to avoid accessing care, even when desperately needed. ${ }^{11}$ Such fears are particularly notable for refugees without health care insurance and those who are undocumented or without legal status. Further, refugee newcomers may be uniquely affected by COVID-19 due to the relatively higher rates of mental health concerns related to their experiences of forced displacement and premigration exposure to trauma (war, torture, persecution, and other human rights abuses). ${ }^{4-6}$ Refugee newcomers' mental health concerns are likely to be compounded by the heightened levels of collective and individual anxiety and uncertainty during this time. Moreover, anxieties about seeking emergency services in a health care system that is already viewed as inaccessible, biased, or stigmatizing can add to peoples' distress-not to mention without in-person support from trusted family or friends. Other factors include limited interpretation services, limited help in understanding and navigating the health care systems, and delays in processing claims for asylum and applications for benefits. These challenges are exacerbated for patients who are responsible for children or child patients who are navigating care with adult caregivers encumbered by psychosocial stress. ${ }^{12,13}$

Describing the provision of care for immigrants in the Bronx, New York during COVID-19, Ross et al added numerous challenges to the myriad factors disrupting care for newcomers, including reduced use of bedside or in-person interpreters (including family members) and difficulties with conveying empathy and making a human connection through masks. ${ }^{14}$ The authors also noted that immigrants are disproportionately affected due to their susceptibility to misinformation (particularly those with limited English language proficiency), increased likelihood to have employment deemed essential (requiring in-person work), and tendency to live in multigenerational households, where shared spaces, such as bathrooms, precludes social distancing and isolation if someone becomes sick. While not explicitly discussed, these challenges are certainly relevant to refugee newcomers.

Of course, many of the aforementioned barriers may be experienced to some extent by other marginalized groups (eg, immigrant, visible minorities, Indigenous, and homeless community members). ${ }^{9,15,16}$ That being said, tendency for these factors to aggregate and combine within-persons suggests that particular attention to the experience of refugee newcomers is warranted. Indeed, the perspective of amalgamating and exacerbating risk factors is commensurate with the perspectives of intersectionality ${ }^{17,18}$ and cumulative risk, ${ }^{19,20}$ whereby single health risks in isolation convey little harm, while many combined risks convey great harm. At the best of times, these barriers pose challenges to refugee newcomers' access to care, though there are many health care professionals who do their best to accommodate their patients' needs. It is important to note that this article is focused on the experience of refugee newcomers in suburban and urban contexts. Presently, we do not cover the experiences of the millions of refugees residing in camps around the world, who are at additional risk due to ethno-religious and political reasons, the dense concentration of displaced people, and the severe lack of resources. ${ }^{21}$

\section{Waterloo Region (Ontario, Canada) and Sanctuary Refugee Health Centre}

Consistent with research on the social determinants of health among refugee newcomers, a 2019 study 
of 1090 immigrants ( $\mathrm{n}=339$ refugees) living in Waterloo Region found that newcomers experience language (44\%), lack of sufficient information (25\%), lack of knowledge of services (47\%), high cost of services $(14 \%)$, and unfriendly staff $(8 \%)$ as barriers to accessing services. ${ }^{22}$ In addition, refugees in Waterloo Region are more likely than other immigrants to have five or more people $(39 \%$ vs $27 \%)$ and two or more generations (73\% vs $61 \%)$ living in one household..$^{22}$ Moreover, $60 \%$ of refugees reported a household income of less than $\$ 30,000 .^{22}$ In this context, Sanctuary Refugee Health Centre (Sanctuary) operates as a not-forprofit primary care clinic and hub for health and mental health services solely for refugee newcomers in Kitchener-Waterloo, Ontario. Sanctuary strives to provide culturally sensitive, trauma-informed, and appropriate services for refugees. ${ }^{23}$

As of May 2020, Sanctuary provides health care services for more than 5000 registered patients with more than 1000 individuals on the waiting list—all of whom came to Canada as refugees. Sanctuary's patients identify 84 different countries of origin and 77 different first languages, the most common of which are Arabic, Tigrinya, Spanish, Somali, and Turkish. Consistent with previous research on the physical and mental health of refugees, ${ }^{2}$ the majority of Sanctuary's patients come from settings with a high burden of tuberculosis and other underlying medical conditions (e.g., heart disease, hypertension, diabetes, chronic respiratory diseases, cancer) as consequences of hardships and traumatic situations they endured before, during, and postmigration (high burden countries, refugee camps, etc). Their chronic health conditions heighten their risk for serious complications arising from COVID-19.

Among Sanctuary's patients, $45.3 \%$ are under 20 years of age, compared with $23 \%$ of Ontario's population; and only $3.1 \%$ are 65 years and older, compared with $16.7 \%$ of Ontario's population. Given the age profile, added risk comes from the fact that Sanctuary's patients are proportionally more likely to be ambulatory carriers of the COVID-19 virus. Emerging evidence shows that, while younger people who contract COVID-19 have a lower mortality rate, they are still vulnerable to contracting the virus and are thus vital in the fight to reduce the spread. ${ }^{24}$ Further, the fact that refugee newcomers are likely to live in more populated and multigenerational dwellings presents concerns regarding the adherence to social distancing policies and the potential for increased rates of exposure for Sanctuary's older patients.

Consistent with the younger demographic, the Sanctuary clinic has a high birth rate. Based on the number of Sanctuary's pregnant patients, more than 350 births are projected for the 2020 calendar year. This is of particular concern at the clinic, given the uncertainty regarding potential long-term consequences and transmissibility if pregnant women contract COVID-19. Notwithstanding these important risk factors, it is important to simultaneously acknowledge the many strengths and resilience factors of many refugee newcomers in relation to the COVID-19 crisis. These may be related to past experiences of dealing with disease, conflict, disaster, and social disruption in their homelands and other countries through which they have journeyed on their pursuit of refuge. ${ }^{25}$ For example, research has shown that refugee women tend to have a lower crude birth rate, infant mortality rate, maternal mortality rate, and percentage of low birth weight than women in both their host country and their country of origin. ${ }^{26}$

Sanctuary has always been committed to making services accessible to refugees, even when they are not covered by health insurance. While most sponsored refugees will come under the Interim Federal Health Program (IFHP) ${ }^{27}$ on arrival for the first year, some must apply for coverage. Eligibility for coverage from the Ontario Health Insurance Plan (OHIP) requires one to reside in Ontario for a minimum of 3 months and also involves completion of an application form. ${ }^{28}$ For those refugees seeking asylum, their access to health coverage and social services depends on their preliminary claim being accepted, which can take up to 3 weeks. Sanctuary has provided care for refugee newcomers during this waiting period at no cost or has facilitated their access to care from other providers as a charitable organization. For example, Sanctuary cared for a pregnant woman who showed up at Sanctuary in acute crisis, septic with a malaria flareup, 3 days after arriving in Canada. Despite the woman's lack of health insurance and her not being a patient of the clinic on arrival, Sanctuary was able to quickly triage her, facilitate her admission to hospital, coordinate her care with the hospital's infectious disease and antenatal care programs and, with the help of Sanctuary's volunteers, provide childcare at the clinic for the woman's young children for the 4 
days she was in the hospital. Notably, Ontario has temporarily suspended the 3-month requirement during the COVID-19 pandemic. ${ }^{28}$

\section{How Sanctuary Has Responded to COVID-19}

The number of patients seeking care in the clinic dropped by approximately $50 \%$ in the days following the Government of Ontario's declaration of a state of emergency on March $17 .{ }^{29}$ The decrease is important for reducing the spread of COVID-19 and has been facilitated by the Province of Ontario releasing new temporary physician billing codes for telehealth services. ${ }^{30}$ However, this presents its own set of challenges, with regard to traumainformed, patient-centered care for families with diverse cultural and linguistic backgrounds. Sanctuary has implemented several measures to continue services and to maintain a safe environment for staff and patients. Sanctuary has cancelled all nonessential clinic activities and has adopted Ontario's billing codes for telemedicine. Where possible, appointments are conducted over the phone or video and interpretation is provided when needed. Efforts are made to serve patients' needs remotely and to see a patient in person only after a provider has had a virtual consult. To facilitate this, Sanctuary staff now phone each patient who has an appointment early in morning, triage problems and complaints, and establish a time for a virtual consultation. They advise patients to stay at home in the interim and call immediate attention to a service provider when there might be an emergency. Walk-ins of patients who do not have appointments has been a longstanding challenge and there are those who seek help in person regardless of the advice given. Patients in distress are appropriately screened at the entrance and escorted to an isolation room for further examination if showing symptoms of COVID-19. Administrative staff are working remotely and most volunteers, especially those who are older, are taking vacation.

Beyond these relatively standard measures, the emerging crisis has led to the following recommendations for providing services to refugee newcomers during the COVID-19 crisis: (1) consider social determinants of health; (2) provide services through a trauma-informed lens; (3) increase focus on continuity of health and mental health care; (4) mobilize support from International Medical Graduates; and (5) diversify communication efforts.

\section{Consider Social Determinants of Health}

Economic insecurity, racism, stigma, problems related to documentation, employment, interpersonal and relationship distress, domestic violence, child abuse, and related challenges are likely to be exacerbated in times of crisis. ${ }^{31,32}$ Thus, it is particularly important to continue to pay attention to these social determinants of health for refugee newcomer patients in the context of the COVID-19 pandemic. Having open communication about patients' situations and how COVID-19 has affected their socioeconomic circumstances and social and familial relationships can provide important insight into the factors that may be affecting their health status. Asking relevant questions can demonstrate caring and removes the onus of initiating the disclosure of challenges from the patient. It can also enable the patient to share information that can inform a discussion about potential resources and additional supports that might be available to them in their community.

\section{Provide Services through a Trauma-Informed Lens}

The provision of services through a traumainformed lens is an important consideration for providing care to refugees. Trauma-informed care ensures that services foster a sense of safety, security, and trust and that the services are informed by the patient's history of trauma. This is particularly critical during COVID-19 because the conditions and emergency policies may resemble those from which they fled in their home countries and may thereby pose risk of retraumatization. ${ }^{33}$ Unfortunately, the emerging crisis challenges the culture of welcome and safety that is so important to staff and patients alike. To overcome issues of mistrust and perceived lack of safety, the staff at Sanctuary dedicate a substantial amount of time to developing trusting relationships with their patients, including taking time to listen to the patient and get a thorough understanding of their past and current experiences and needs and ensure that the patient retains a sense of control and involvement in decisions about their care.

\section{Increase Focus on Continuity of Health and Mental Health Care}

Lockdowns and infections may worsen the emotional situation of refugee patients. Many community programs that normally support refugee newcomers, such as food banks, shelters, children's camps, 
language classes, sports activities, and community gatherings have been canceled. The overarching crisis, coupled with resultant economic stressors, closures of important community programs, and social isolation may influence other aspects of health, personal care, and interpersonal relationships in addition to compliance with COVID-19 preventative efforts. It is recommended that, whenever possible, people with preexisting health and mental health conditions continue with their treatment and be aware of new or worsening symptoms. ${ }^{34}$ Telephone and video interventions can include brief assessment and motivational interviewing around mental health strategies during the state-of-emergency as well as full therapy sessions. Virtual platforms can enable the continuation of care while minimizing in-person appointments, though challenges related to technical skills and interpretation services and costs are certainly a barrier. It is also important to be mindful of technological access barriers. For example, it is often the case that newcomers do not have a landline or mobile plan but can connect via other online platforms that comply with privacy standards. In some cases, to access patients virtually, use of platforms that are not compliant with the jurisdictional health information protection acts may be necessary as a first step to provide telemedicine for virtually hard-to-reach patients.

\section{Mobilize Support from International Medical Graduates}

During COVID-19, Sanctuary has used the expertise of International Medical Graduates to triage patients over the phone. Sanctuary has been able to redeploy the help of one internationally trained physician and nurse from administrative positions, which they had filled while working to acquire Canadian credentials for practice. These individuals triage the nature and expressed urgency of a patient's problems based on federal guidelines ${ }^{35}$ and make a referral to Public Health if patients exhibit COVID-19 symptoms. They have language skills, cultural sensitivity, and medical backgrounds that enable them to respond with patience and empathy to each patient seeking an appointment over the phone.

\section{Diversify Communication Efforts}

Many refugee newcomers do not have linguistic competence in the vernacular, making it difficult or impossible to read and understand official information and announcements concerning reducing the spread of COVID-19. Graphics and translations of official correspondence can help ameliorate this challenge. The UN Regional Risk Communication and Community Engagement Working group 36 has recommended diversifying communication tools and format, simplifying messages, and testing messages with refugees. ${ }^{36}$ Accordingly, Sanctuary has produced educational materials with basic public health and prevention guidelines regarding COVID-19 in the most common languages (see supplemental materials). As of April 11, 2020, materials have been made available in English, Spanish, Turkish, Arabic, Tigrinya, and Amharic. Sanctuary has posted the materials at various locations onsite and on Sanctuary's website.

\section{Conclusion}

The rapid spread of COVID-19 has led to tremendous difficulty for health care providers across the world. While all citizens are at risk, refugee newcomers have a unique constellation of risk and protective factors that must be considered to ensure the appropriate provision of primary care during the COVID-19 crisis, in addition to the delivery, access, and uptake of all health and social services. These challenges are sweeping and cut across layers of organization in the health care system, from primary care services to emergency, intensive, and tertiary care, to public health initiatives and global prevention efforts. To support the wellbeing of refugees during the COVID-19 crisis, it is critical for health care service providers and practice briefings to adhere to principles of trauma-informed, linguistically tailored, and culturally sensitive health care. In the coming weeks and months, these principles will become increasingly important, in addition to considerations regarding the management of existing medical problems and prevention efforts for other, long-term conditions interacting with COVID-19 related illness. We remain hopeful and optimistic for these goals, as the response from medical and allied health professionals has been nothing short of remarkable.

We would like to thank Eda Dede for providing key information about how Sanctuary has implemented educational materials for their patients.

To see this article online, please go to: http://jabfm.org/content/ 34/Supplement/S210.full. 


\section{References}

1. Hadgkiss EJ, Renzaho AM. The physical health status, service utilisation and barriers to accessing care for asylum seekers residing in the community: a systematic review of the literature. Aust Health Rev 2014;38:142-59.

2. Mangrio E, Forss KS. Refugees' experiences of healthcare in the host country: a scoping review. BMC Health Serv Res 2017;17.

3. McKeary M, Newbold B. Barriers to care: The challenges for Canadian refugees and their health care providers. Journal of Refugee Studies 2010;23: 523-45.

4. Porter M, Haslam N. Predisplacement and postdisplacement factors associated with mental health of refugees and internally displaced persons. JAMA 2005;294:602-12.

5. Silove D, Ventevogel P, Rees S. The contemporary refugee crisis: an overview of mental health challenges. World Psychiatry 2017;16:130-9.

6. Kien C, Sommer I, Faustmann A, et al. Prevalence of mental disorders in young refugees and asylum seekers in European countries: a systematic review. Eur Child Adolesc Psychiatry 2019;28: 1295-310.

7. Williamson DL, Stewart MJ, Hayward K, et al. Low-income Canadians' experiences with healthrelated services: implications for health care reform. Health Policy 2006;76:106-21.

8. Stewart MJ, Neufeld A, Harrison M, Spitzer D, Hughes K, Makwarimba E. Immigrant women family caregivers in Canada: implications for policies and programmes in health and social sectors. Health Soc Care Community 2006;14:329-40.

9. Ahmed S, Shommu NS, Rumana N, Barron GRS, Wicklum S, Turin TC. Barriers to access of primary healthcare by immigrant populations in Canada: a literature review. J Immigr Minor Health 2016; 18:1522-40.

10. Morris MD, Popper ST, Rodwell TC, Brodine SK, Brouwer KC. Healthcare barriers of refugees postresettlement. J Community Health 2009;34:529-38.

11. Khullar D, Chokshi DA. Challenges for immigrant health in the USA - the road to crisis. Lancet 2019;393:2168-74.

12. Browne DT, Kumar A, Puente-Duran S, Georgiades K, Leckie G, Jenkins J. Emotional problems among recent immigrants and parenting status: findings from a national longitudinal study of immigrants in Canada. PLOS One 2017;12: $\mathrm{e} 0175023$.

13. Browne DT, Wade M, Prime H, Jenkins JM. School readiness amongst urban Canadian families: risk profiles and family mediation. J Educ Psychol 2018;110:133-46.

14. Ross J, Diaz CM, Starrels JL. The disproportionate burden of COVID-19 for immigrants in the
Bronx, New York. JAMA Intern Med 2020; 180:1043.

15. Marrone S. Understanding barriers to health care: a review of disparities in health care services among indigenous populations. Int J Circumpolar Health 2007;66:188-98.

16. Ramsay N, Hossain R, Moore M, Milo M, Brown A. Health care while homeless: barriers, facilitators, and the lived experiences of homeless individuals accessing health care in a Canadian regional municipality. Qual Health Res 2019;29:1839-49.

17. Viruell-Fuentes EA, Miranda PY, Abdulrahim S. More than culture: structural racism, intersectionality theory, and immigrant health. Soc Sci Med 2012;75:2099-106.

18. Gkiouleka A, Huijts T, Beckfield J, Bambra C. Understanding the micro and macro politics of health: Inequalities, intersectionality \& institutions A research agenda. Soc Sci Med 2018;200:92-8.

19. Evans GW, Li D, Whipple SS. Cumulative risk and child development. Psychol Bull 2013;139: 1342-96.

20. Zhang J, Savla J, Cheng HL. Cumulative risk and immigrant youth's health and educational achievement: mediating effects of inter- and intra-familial social capital. Youth Soc 2019;51:793-813.

21. Canadian Broadcasting Corporation. Aid workers brace for impact of coronavirus in refugee camps. 2020. Available at: https://www.cbc.ca/news/world/ aid-workers-brace-for-impact-of-coronavirus-inrefugee-camps-1.5506172. Accessed Mar 23, 2020.

22. Immigration Partnership of Waterloo Region. Immigration matters survey 2019: full report. 2019. Available at: https://www.immigrationwaterlooregion. ca/en/resources/Surveys/Immigration-Matters-SurveyReport-2019.pdf.

23. Basabose JD, Smith JA, Stephenson MC, Brockett M, Browne DT. Promoting family well-being and resilience of refugee newcomers in Waterloo region: The Sanctuary Refugee Health Centre. Canadian Diversity 2020;17:94-99.

24. Centers for Disease Control and Prevention. Severe outcomes among patients with Coronavirus disease 2019 (COVID-19) - United States, February 12March 16. MMWR Morb Mortal Wkly Rep. 2020;69:343-6. doi: 10.15585/mmwr.mm6912e2.

25. Masten AS, Narayan AJ. Child development in the context of disaster, war and terrorism: Pathways of risk and resilience. Annu Rev Psychol 2012;63:227-57.

26. Hynes M, Sheik M, Wilson HG, Spiegel P. Reproductive health indicators and outcomes among refugee and internally displaced persons in postemergency phase camps. JAMA 2002;288:595-603.

27. Government of Canada. Interim Federal Health Program: Summary of coverage. 2019. Available at: https://www.canada.ca/en/immigration-refugeescitizenship/services/refugees/help-within-canada/ 
health-care/interim-federal-health-program/coveragesummary.html. Accessed May 20, 2020.

28. Government of Ontario. Apply for OHIP and get a health card. 2010. Available at: https://www.ontario. $\mathrm{ca} /$ page/apply-ohip-and-get-health-card. Accessed May 20, 2010.

29. Government of Ontario. Ontario enacts declaration of emergency to protect the public: Significantly enhanced measures will help contain spread of COVID-19. 2020. Available at: https://news.ontario. ca/opo/en/2020/03/ontario-enacts-declaration-ofemergency-to-protect-the-public.html. Accessed March 20, 2020.

30. Government of Ontario. OHIP Bulletin 11229: Prima ry care changes in response to Corona Virus (COVID19) effective March 14, 2020. 2020. Available at: http:// health.gov.on.ca/en/pro/programs/ohip/bulletins/ 11000/bul11229.pdf. Accessed March 20, 2020.

31. Lee D, Brooks-Gunn J, McLanahan SS, Notterman D, Garfinkel I. The Great Recession, genetic sensitivity, and maternal harsh parenting. PNAS. 2013;110: 13780-4.

32. Schneider W, Waldfogel J, Brooks-Gunn J. The Great Recession and risk for child abuse and neglect. Child Youth Serv Rev 2017;72:71-81.
33. Júnior JG, de Sales JP, Moreira MM, Pinheiro WR, Lima CKT, Neto MLR. A crisis within the crisis: The mental health situation of refugees in the world during the 2019 coronavirus (2019-nCoV) outbreak. Psychiatry Res 2020;288:113000.

34. Centers for Disease Control and Prevention. Mental health and coping during COVID-19. 2020. Available at: https://www.cdc.gov/coronavirus/2019ncov/prepare/managing-stress-anxiety.html. Accessed March 24, 2020.

35. Government of Canada. Interim national surveillance guidelines for human infection with Coronavirus disease (COVID-19). 2020. Available at: https://www.canada.ca/en/public-health/services/ diseases/2019-novel-coronavirus-infection/healthprofessionals/interim-guidance-surveillance-humaninfection.html. Accessed March 21, 2020.

36. UN Regional Risk Communication and Community Engagement Working Group. COVID-19: How to include marginalized and vulnerable people in risk communication and community engagement. 2020. Available at: https://interagencystandingcommittee.org/ covid-19-how-include-marginalized-and-vulnerablepeople-risk-communication-and-community-engage ment. Accessed March 20, 2020. 